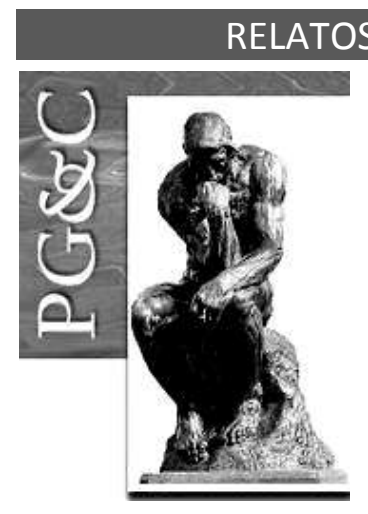

\title{
POLÍTICAS DE GESTÃO DO CONHECIMENTO: DA TEORIA À PRÁTICA
}

\author{
Fábio Corrêa \\ Doutor em Sistemas de Informação e Gestão do Conhecimento pela \\ Universidade FUMEC Brasil. Professor da Universidade FUMEC, Brasil. \\ E-mail: fabiocontact@gmail.com

\section{Cláudio Paixão Anastácio de Paula} \\ Doutor em Psicologia Social pela Universidade de São Paulo, Brasil. \\ Professor da Universidade Federal de Minas Gerais, Brasil. \\ E-mail: claudiopap@hotmail.com

\section{Jurema Suely de Araujo Nery Ribeiro} \\ Doutora em Sistemas de Informação e Gestão do Conhecimento pela \\ Universidade FUMEC, Brasil. Professora da Universidade FUMEC, Brasil. \\ E-mail: jurema.nery@gmail.com \\ Renata de Souza França \\ Doutora em Sistemas de Informação e Gestão do Conhecimento pela \\ Universidade FUMEC, Brasil. Professora da Universidade do Estado de \\ Minas Gerais, Brasil. \\ E-mail: profrenatafranca@gmail.com

\section{Eric de Paula Ferreira} \\ Doutor em Sistemas de Informação e Gestão do Conhecimento pela \\ Universidade FUMEC, Brasil. Professor da Universidade do Estado de \\ Minas Gerais, Brasil. \\ E-mail: eric.p.f@gmail.com
}

\begin{abstract}
Resumo
As políticas de Gestão do Conhecimento são instrumentos que estabelecem norteamentos com impacto direto em múltiplos níveis e, nesse sentido, necessitam ser abordadas em uma perspectiva holística. Neste sentido, esta pesquisa objetiva analisar políticas de Gestão do Conhecimento para identificar os fatores que as fundamentam, visando elucidar se a visão holística teórica converge para a prática estabelecida por essas políticas. Por procedimentos metodológicos adotou-se as abordagens qualitativa e quantitativa, valendo-se da Análise de Conteúdo e método percentílico, respectivamente. Foram analisadas políticas de Gestão do Conhecimento atinentes ao intervalo temporal de 2001 a $2018 \mathrm{em}$ organizações públicas, a saber: Serviço Federal de Processamento de Dados, Governo do Estado de São Paulo, Instituto de Pesquisa Econômica Aplicada, Secretaria de Estado de Planejamento e Gestão de Minas Gerais, Secretaria de Estado de Fazenda de Minas Gerais, Empresa Brasileira de Correios e Telégrafos e Governo do Estado de Rondônia. Conclui-se que, dentre as políticas analisadas, nenhuma contempla todos os fatores indispensáveis para o sucesso da Gestão do Conhecimento, não atingindo os níveis necessários para o enquadramento na perspectiva holística. Contudo, a teoria converge com a prática, pois todos os fatores foram contemplados por pelo menos uma política de Gestão do Conhecimento e todas as políticas contemplam mais de um fator. Os resultados sugerem que as organizações têm capacidade para elaborar políticas que contemplem o gerenciamento do conhecimento de forma holística, porém, esses norteamentos devem ser operacionalizados na prática para que isso seja feito de modo exitoso.
\end{abstract}

Palavras-chave: Gestão do Conhecimento. Política. Política Pública. Holísmo.

Perspectivas em Gestão \& Conhecimento, João Pessoa, v. 11, número especial, p. 18-34, mar. 2021. DOI: http://dx.doi.org/10.22478/ufpb.2236-417X.2021v11nEspecial.57561

http://periodicos.ufpb.br/ojs2/index.php/pgc. ISSN: 2236-417X. Publicação sob Licença (cc) EY-NC-ND 


\title{
KNOWLEDGE MANAGEMENT POLICIES: FROM THEORY TO PRACTICE
}

\begin{abstract}
Knowledge Management policies are instruments that establish guidelines with direct impact at multiple levels and, in this sense, need to be approached in a holistic perspective. In this sense, this research aims to analyze Knowledge Management policies to identify the factors that underlie them, aiming to elucidate whether the theoretical holistic view converges to the practice established by these policies. By methodological procedures, qualitative and quantitative approaches were adopted, using Content Analysis and percentile method, respectively. Knowledge Management policies from 2001 to 2018 in public organizations were analyzed, namely: Federal Data Processing Service, Government of the State of São Paulo, Institute of Applied Economic Research, State Secretariat for Planning and Management of Minas Gerais, Minas Gerais State Finance Department, Brazilian Post and Telegraph Company and Rondônia State Government. It is concluded that, among the analyzed policies, none contemplates all the indispensable factors for the success of the Knowledge Management, not reaching the necessary levels for the framing in the holistic perspective. However, theory converges with practice, since all factors were covered by at least one Knowledge Management policy and all policies include more than one factor. The results suggest that organizations have the capacity to develop policies that contemplate knowledge management in a holistic way, however, these guidelines must be operationalized in practice for this to be done successfully.
\end{abstract}

Keywords: Knowledge management. Policy. Public policy. Holism.

\section{INTRODUÇÃO}

A enredamento entre Políticas públicas e a Gestão do Conhecimento (GC) tem guarida na perspectiva holística, especificamente tratada por Souza (2006) e Corrêa e Carvalho (2019), respectivamente. Política pública se apresenta como um instrumento que medeia a relação entre agentes e suas acepções "assumem, em geral, uma visão holística do tema, uma perspectiva de que o todo é mais importante do que a soma das partes e que indivíduos, instituições, interações, ideologia e interesses contam, mesmo que existam diferenças sobre a importância relativa destes fatores" (SOUZA, 2006, p. 25, grifo nosso). Trata-se de um instrumento que estabelece norteamentos que impactam outrem ${ }^{1}$ e que envolve múltiplos fatores (partes), como supracitado.

Os estudos de Weil (1991), Capra (2000), Pereira (2002), Maciel e Silva (2008), Crema (2015), Natale, Neves e Carvalho (2016), Silveira et al. (2017), Ramalho, Locatelli e Silva (2018) e Gonzalez, Martins e Melo (2018) assinalam que a perspectiva reducionista, que contempla partes específicas do todo de modo disjunto, é substancialmente aplicada em diversos contextos e traz consigo implicações filosóficas, políticas, sociais e econômicas (CAPRA, 2014). A perspectiva holística, que promulga tratar concomitantemente as partes do todo é uma alternativa complementar ao reducionismo, sendo defendida, especificamente no campo da GC, por Holsapple e Joshi (1999), Rubenstein-Montano et al. (2001), Heisig (2009), Fteimi (2015) e Corrêa (2020).

Corrêa e Carvalho (2019) defendem que, por ser essa uma forma de gestão amparada no conhecimento organizacional, a GC deve assumir a perspectiva holística como um sustentáculo desse campo. Ao envolver diversos fatores (partes) como gestão de recursos humanos, tecnologia, cultura, dentre ouros que se influenciam a "GC deve contemplar todas

\footnotetext{
${ }^{1}$ Termo adotado para referenciar múltiplos níveis, como indivíduos, instituições, organizações, governos e cidadãos assinalados por Souza (2006), Gonçalves (2006) e Brasil (2007).
}

Perspectivas em Gestão \& Conhecimento, João Pessoa, v. 11, número especial, p. 18-34, mar. 2021. 
as partes do gerenciamento do conhecimento em conjunto, preservando as conexões adjacentes de modo a se atingir uma gestão íntegra do conhecimento" ${ }^{2}$ (CORRÊA; CARVALHO, 2019 , p. 2, tradução nossa, grifo nosso).

Desse modo, uma política de GC apresenta-se como um instrumento que estabelece, de forma normativa, o que deve ser feito em determinado contexto sobre a ótica do conhecimento. Por conseguinte, considerando a síntese de que ambas são amparadas pela perspectiva holística que apregoa que as partes - fatores - devem ser reconhecidas e tratadas em conjunto, emerge o seguinte questionamento: em que nível as políticas de GC tem contemplado os fatores críticos para o sucesso dessa iniciativa? Por meio deste nível torna-se possível avaliar se essas políticas contemplam a GC em sua totalidade holística ou parcialmente. Sustentada nesta interrogativa, esta pesquisa tem por objetivo analisar políticas de GC para identificar os fatores que as fundamentam. Especificamente, busca-se identificar políticas de GC (a) e analisa-las mediante aos fatores considerados críticos para o sucesso do gerenciamento do conhecimento (b), de modo a elucidar o nível percentílico em que tais políticas têm contemplado esses fatores (c).

Haja vista que a GC é um campo de pesquisa atinente a sociedade contemporânea do conhecimento, a referida análise tende a revelar se a teoria do gerenciamento do conhecimento converge com a prática organizacional promovida pelas políticas de GC, ilustrando a importância desta pesquisa na esfera acadêmica-organizacional. Isso suscita relevância por permitir refletir se a teoria tem se mostrado alinhada às práticas institucionais, de modo a compreender melhor como tem se apresentado a relação teoria-prática.

Neste sentido, esta pesquisa é subdividida em seções. Primeiramente (seção 2), são apresentados os alicerces teóricos para a condução desta investigação e, por conseguinte (seção 3), são explanados os procedimentos metodológicos utilizados. Os resultados (seção 4) evidenciam os achados, sendo sucedidos pelas conclusões (seção 5) acerca da problemática proposta. As referências findam esta pesquisa.

\section{REFERENCIAL TEÓRICO}

Política pública consiste no ajustamento de dois termos que devem ser interpretados separadamente para um entendimento preciso. Neste sentido, a pesquisa de Gonçalves (2006) é singular por clarificar esses termos, sendo política "um princípio, um plano ou curso de ação a ser seguido por um governo, uma organização ou indivíduo" (GONÇALVES, 2006, p. 37). Segundo essa mesma pesquisadora uma política se torna pública quando implica efeito à sociedade. No contexto de uma organização uma política torna-se pública por incidir sobre seus funcionários e, ou, no contexto social de sua atuação. Estabelece-se, no restante deste texto, o termo política como abreviação para referenciar a terminologia Política pública.

Segundo Souza (2006, p. 26), a formulação de políticas consiste no estágio em que instituições "traduzem seus propósitos [...] em programas e ações que produzirão resultados ou mudanças no mundo real". Por conseguinte, Procopiuck (2013, p. 139) alude que a função de uma política é "prover orientações normativas, guiadas por valores e por finalidades, para a elaboração de estratégias, programas e planos que procuram adequar meios para atingir determinados fins". Desse modo, uma política é um instrumento que estabelece norteamentos que impactam outrem.

Por estabelecer caminho(s) que afluem para outrem uma política não necessariamente prescreve como fazer, pois consiste em orientações normativas, mas o que deve ser

\footnotetext{
2 Do original "KM [...] should comprehend all parts of knowledge management together, preserving adjacent connections to achieve integrated management of organisational knowledge" (CORRÊA; CARVALHO, 2019, p. 2).
}

Perspectivas em Gestão \& Conhecimento, João Pessoa, v. 11, número especial, p. 18-34, mar. 2021. 
considerado para ser feito sobre determinado assunto. Por essa característica uma política é alicerçada em premissas e diretrizes, sendo uma premissa uma base para a constituição de um raciocínio, sucedida de diretrizes que instruem quanto ao que deve ser feito. Mediante a relevância do conhecimento na sociedade contemporânea emergem as políticas de GC, estabelecendo premissas e diretrizes a serem consideradas nas tratativas desse campo.

A exemplo, no âmbito governamental o Comitê Executivo do Governo Eletrônico (CEGE), criado por meio de decreto em 18 de outubro de 2000, tem por intento estabelecer diretrizes às entidades da Administração Pública Federal, dentre as quais destaca-se a "formulação de política específica de GC no âmbito das políticas de governo eletrônico" (BRASIL, 2007, p. 45). A formulação dessa política pode ser vista em Brasil (2007, p.65-73), sendo um marco que incute a GC ao contexto público nacional e define esse campo como um

Conjunto de processos sistematizados, articulados e intencionais, capazes de incrementar a habilidade dos gestores e servidores públicos em criar, coletar, organizar, transferir e compartilhar informações e conhecimentos que podem servir para a tomada de decisões, para a gestão de políticas públicas e para a inclusão do cidadão como produtor de conhecimento coletivo (BRASIL, 2007, p. 67, grifo nosso)

Considerando uma política um instrumento norteador que impacta a outrem (sociedade - grifo supracitado) e que deve ser considerado e desenvolvido pelas demais entidades para a qual se destina há de se ponderar que suas premissas e diretrizes estabeleçam os pilares para determinado assunto. Dito de outro modo, uma política de GC tende a estabelecer o que é imperativo de ser feito, mas não como fazê-lo, para a promover o gerenciamento do conhecimento com sucesso. Neste ponto, emerge uma ligação firme entre a prática (política) e a teoria (pesquisas acadêmicas) da GC.

A pesquisa de Corrêa e Carvalho (2019), por meio de uma consolidação de estudos científicos publicados entre 1997 e 2015, estabeleceu 13 áreas impreteríveis para a o sucesso da GC. Essas áreas devem ser trabalhadas em conjunto para que se atinja o gerenciamento do conhecimento de modo exitoso. Mediante a essa perspectiva, têm-se o alinhamento da prática de uma política com a teoria da GC, pois o que é crítico para o sucesso da GC deveria ser contemplado como premissas ou diretrizes em uma política formulada nesse contexto. Essas 13 áreas, denominadas como fatores críticos de sucesso, são representadas por meio do Quadro 1:

Quadro 1 - Fatores Críticos de Sucesso da Gestão do Conhecimento

\begin{tabular}{|l|l|}
\hline $\begin{array}{l}\text { Fator Crítico de } \\
\text { Sucesso }\end{array}$ & Descrição \\
\hline Estratégia & $\begin{array}{l}\text { A estratégia de GC deve ser clara, bem definida e clarificada aos funcionários para } \\
\text { que compreendam os objetivos almejados pela GC. Ademais, essa estratégia deve } \\
\text { ser alinhada a estratégia institucional para apoiar seus objetivos. }\end{array}$ \\
\hline $\begin{array}{l}\text { Liderança e } \\
\text { suporte da alta } \\
\text { administração }\end{array}$ & $\begin{array}{l}\text { O apoio da alta administração atua como um pilar para a continuidade da GC. Os } \\
\text { líderes, enquanto indivíduos que influenciam o comportamento das pessoas, } \\
\text { devem atuar como modelos da GC para os demais. }\end{array}$ \\
\hline $\begin{array}{l}\text { Equipe de } \\
\text { gestão do } \\
\text { conhecimento }\end{array}$ & $\begin{array}{l}\text { Consiste em uma equipe de profissionais específica, orientada para a promoção } \\
\text { da GC. Essa equipe possui papéis e responsabilidades específicos, como } \\
\text { estabelecer processos, coordenar, gerenciar e definir o objetivo da proposta de } \\
\text { GC. }\end{array}$ \\
\hline $\begin{array}{l}\text { Recursos } \\
\text { (financeiro, } \\
\text { humano, } \\
\text { material e }\end{array}$ & $\begin{array}{l}\text { A GC demanda de recursos financeiros para sistemas tecnológicos específicos, } \\
\text { pessoas para sua condução, insumos materiais e de infraestrutura, bem como } \\
\text { tempo para que os funcionários executem os processos e atividades da GC. }\end{array}$ \\
\hline
\end{tabular}

Perspectivas em Gestão \& Conhecimento, João Pessoa, v. 11, número especial, p. 18-34, mar. 2021. 


\begin{tabular}{|c|c|}
\hline $\begin{array}{l}\text { Fator Crítico de } \\
\text { Sucesso }\end{array}$ & Descrição \\
\hline \multicolumn{2}{|l|}{ tempo) } \\
\hline $\begin{array}{l}\text { Processos e } \\
\text { atividades }\end{array}$ & $\begin{array}{l}\text { São o cerne da GC por evidenciarem o manuseio do conhecimento organizacional, } \\
\text { devendo serem integrados ao fluxo de trabalho de forma clara, estruturada e } \\
\text { sistemática. Identificação, armazenamento e compartilhamento são alguns } \\
\text { processos e atividades, também denominados fases, adotados em frameworks, } \\
\text { comumente, de forma não linear. }\end{array}$ \\
\hline $\begin{array}{l}\text { Gestão de } \\
\text { recursos } \\
\text { humanos }\end{array}$ & $\begin{array}{l}\text { As pessoas são o elemento chave da GC, o que torna a gestão de recursos } \\
\text { humanos imprescindível por atuar junto a estes indivíduos detentores do } \\
\text { conhecimento. Assim, os processos de recrutamento, desenvolvimento e retenção } \\
\text { de funcionários municiam a organização de colaboradores com conhecimentos } \\
\text { relevantes e, portanto, são vitais para o sucesso da GC. }\end{array}$ \\
\hline $\begin{array}{l}\text { Treinamento e } \\
\text { educação }\end{array}$ & $\begin{array}{l}\text { O vocabulário da GC se dissocia dos demais e deve ser claro para que seja } \\
\text { compreendido. Assim, os funcionários devem ser treinados e educados para } \\
\text { compreender a terminologia e os objetivos da GC, suas responsabilidades perante } \\
\text { a essa iniciativa e demais aspectos como compartilhamento do conhecimento, } \\
\text { comportamento colaborativo e manuseio das ferramentas voltadas para o } \\
\text { conhecimento. }\end{array}$ \\
\hline Motivação & $\begin{array}{l}\text { São meios para incentivar os funcionários para que se envolvam, compartilhem } \\
\text { seus conhecimentos e atuem de forma colaborativa com a GC. Alguns incentivos } \\
\text { são recompensas (financeiras), gratificações (benefícios não financeiros) e } \\
\text { reconhecimento aos funcionários. }\end{array}$ \\
\hline $\begin{array}{l}\text { Trabalho em } \\
\text { equipe }\end{array}$ & $\begin{array}{l}\text { Uma equipe pode ser interpretada como a reunião de dois ou mais indivíduos que } \\
\text { interagem e se influenciam. Estar em equipe impulsiona a cooperação entre as } \\
\text { pessoas e eleva o sucesso dos processos e atividades da GC. Desse modo, as } \\
\text { equipes de trabalho são benéficas à criação e compartilhamento do conhecimento } \\
\text { organizacional. }\end{array}$ \\
\hline Cultura & $\begin{array}{l}\text { São parâmetros de valores, normas e costumes sociais que moldam a forma como } \\
\text { as pessoas se comportam. Para a GC uma cultura propícia deve fomentar a } \\
\text { partilha do conhecimento, dentre outros aspectos que regem uma atmosfera } \\
\text { voltada ao conhecimento. }\end{array}$ \\
\hline $\begin{array}{l}\text { Tecnologia da } \\
\text { informação }\end{array}$ & $\begin{array}{l}\text { Por uma perspectiva a tecnologia da informação conecta as pessoas em prol do } \\
\text { compartilhamento do conhecimento tácito. Por outra perspectiva permite que o } \\
\text { conhecimento explícito seja armazenado e compartilhado na organização, pelo } \\
\text { uso de banco de dados, intranet e internet. }\end{array}$ \\
\hline Mensuração & $\begin{array}{l}\text { Visa medir o conhecimento para avaliar o progresso e a melhoria contínua do } \\
\text { programa de GC, acarretando na necessidade de determinar metas mensuráveis. } \\
\text { Um instrumento é o diagnóstico, que tende a mensurar aspectos para identificar } \\
\text { lacunas a serem sanadas mediante ao gerenciamento do conhecimento. }\end{array}$ \\
\hline Projeto piloto & $\begin{array}{l}\text { São uma forma de pôr em prática a GC em menor amplitude institucional para } \\
\text { captar os erros e obter lições aprendidas, elevando o sucesso de uma iniciativa } \\
\text { quando aplicada em maior abrangência. }\end{array}$ \\
\hline
\end{tabular}

Fonte: Adaptado de Corrêa e Carvalho (2019, tradução nossa)

Considerando a relevância do conhecimento na sociedade e a criticidade imbuída nesses 13 fatores para a promoção do gerenciamento do conhecimento com sucesso torna-se plausível ansiar que políticas de GC sejam alicerçadas nesses. Isso porque as políticas (prática) e a GC (perspectiva teórica) devem ser tratadas pela perspectiva holística, conforme aludem Souza (2006) e Corrêa, e Carvalho (2019), respectivamente. Desse modo, o elo conectivo entre os 13 fatores supracitados, estabelecidos pela teoria acadêmica, junto a política de GC, materializada como uma prática advinda da ambientação do gerenciamento do conhecimento

Perspectivas em Gestão \& Conhecimento, João Pessoa, v. 11, número especial, p. 18-34, mar. 2021. 
em um contexto real, tende a um alinhamento que pode revelar se políticas dessa natureza estão sendo constituídas de modo abrangente rumo ao sucesso desta iniciativa.

Para analisar se o referido alinhamento se apresenta como fidedigno a seção seguinte desta pesquisa delineia os procedimentos metodológicos que evidenciam como esse exame será realizado.

\section{PROCEDIMENTOS METODOLÓGICOS}

Seguindo os preceitos de Gil (2002) uma pesquisa deve ser classificada pela sua natureza e percurso de investigação. Assim, no que tange a natureza esta pesquisa é descritiva, pois expõe a relação entre as políticas de GC e os fatores que as fundamentam mediante a concepção de que esses são críticos para o sucesso do gerenciamento do conhecimento. Em relação ao percurso investigativo, têm-se a tipificação pela abordagem, técnica de pesquisa e método analítico.

O percurso investigativo desta pesquisa é alicerçado em três etapas, a saber: identificar políticas de GC (a), analisa-las mediante aos fatores considerados críticos para o sucesso do gerenciamento do conhecimento (b) e elucidar o nível percentílico em que tais políticas têm contemplado esses fatores (c). Para identificar políticas de GC (a) foi realizada busca nas bases SPELL e Scielo ${ }^{3}$ por meio das palavras-chave "política" and "gestão do conhecimento", não sendo obtido nenhum resultado ${ }^{4}$. Então, partiu-se para a pesquisa em formato livre, na qual cada autor deste manuscrito promoveu buscas na internet, culminando em sete políticas de GC (Quadro 2). Por fazer uso de artefatos públicos a técnica de pesquisa é classificada como documental (GIL, 2002).

Quadro 2 - Instituições das Políticas de Gestão do Conhecimento identificadas

\begin{tabular}{|l|l|l|}
\hline Instituição & Sigla & Referência \\
\hline Serviço Federal de Processamento de Dados & SERPRO & Macedo et al. (2001) \\
\hline Governo do Estado de São Paulo & GovSP & Brasil (2009) \\
\hline Instituto de Pesquisa Econômica Aplicada & IPEA & IPEA (2010) \\
\hline $\begin{array}{l}\text { Secretaria de Estado de Planejamento e Gestão de Minas } \\
\text { Gerais }\end{array}$ & SEPLAG/MG & Minas Gerais (2012) \\
\hline Secretaria de Estado de Fazenda de Minas Gerais & SEF/MG & $\begin{array}{l}\text { Oliveira e Silva } \\
\text { (2013) }\end{array}$ \\
\hline Empresa Brasileira de Correios e Telégrafos & ECT & Batista et al. (2014) \\
\hline Governo do Estado de Rondônia & GovRO & Brasil (2018) \\
\hline
\end{tabular}

Fonte: Dados da pesquisa (2020)

Por conseguinte, para analisar as políticas de GC identificadas mediante aos fatores considerados críticos para o sucesso do gerenciamento do conhecimento (b) foi promovido o exame textual destes documentos. O método analítico utilizado foi a Análise de Conteúdo (BARDIN, 1977), sendo os 13 fatores expostos por Corrêa e Carvalho (2019) as categorias de análise fechadas, por serem determinados a priori. Os documentos foram lidos sob o intento de identificar a presença dos 13 fatores supracitados, imprimindo o emprego da abordagem qualitativa (MINAYO, 1998). Cientes da subjetividade existente nesta abordagem as citações diretas foram utilizadas costumeiramente, de modo a permitir o entendimento das inferências realizadas e consultas aos documentos originais.

\footnotetext{
${ }^{3}$ http://www.spell.org.br/ e https://www.scielo.br/.

${ }_{4}$ A escolha das referidas bases foi amparada na representatividade de periódicos indexados e as palavras-chave foram determinadas pela exatidão que esses termos representam nesta pesquisa.
}

Perspectivas em Gestão \& Conhecimento, João Pessoa, v. 11, número especial, p. 18-34, mar. 2021. 
Para elucidar o nível percentílico em que tais políticas têm contemplado esses fatores (c) fez-se uso da abordagem quantitativa (MINAYO, 1998). Assim, face aos fatores identificados nas políticas de GC aplicou-se o método percentílico, de modo a obter o grau de presença dos 13 fatores nas políticas examinadas. Isso permite revelar em que nível essas políticas tem considerado o que é crítico para o sucesso da GC, haja vista que, segundo Souza (2006) e Corrêa e Carvalho (2019), esses fatores devem ser tratados pela perspectiva holística, ou seja, em conjunto. A seção seguinte explana os resultados deste processo investigativo.

\section{RESULTADOS}

As sete políticas a serem analisadas são oriundas de instituições públicas, sendo necessário uma breve caracterização das mesmas para entendimento do contexto de atuação. Desse modo, prossegue-se com a descrição da amostra (subseção 4.1), constituídas pelas instituições que apresentam as políticas a serem analisadas, para, posteriormente, realizar a análise (subseção 4.2) sobre suas políticas de GC.

\subsection{Descrição amostral}

O Serviço Federal de Processamento de Dados (SERPRO) é "uma empresa estatal de prestação de serviços" (CARVALHO, 2000, p. 120) de "Tecnologia da Informação e Comunicações a serviço da administração pública brasileira" (CARVALHO; MENDES; VERAS, 2006 , p. 10) e suas conformações seguem o modelo público do Estado. O processo de GC do SERPRO "consiste em um conjunto de componentes: Políticas, Diretrizes, Práticas Empresariais, Comitê de Representantes de Gestão do Conhecimento e Gestores dos instrumentos que apoiam as práticas [...] em todos os níveis da organização (SERPRO, 2004, sem número). Outra instituição que apresenta uma política de GC é a Empresa Brasileira de Correios e Telégrafos (ECT), também denominada Correios, sendo uma empresa pública federal criada em 20 de março de 1969 com o intento de oferecer soluções em comunicação (BATISTA et al, 2014).

Na esfera da gestão pública têm-se o Governo do Estado de São Paulo (GovSP), o qual fora governado por José Serra que, no âmbito de suas atribuições legais, anunciou o decreto N. 53.963 de 21 janeiro de 2009, instituindo a Política de Gestão do Conhecimento e Inovação na Administração Pública Estadual (BRASIL, 2009). No mesmo contexto têm-se o Governo do Estado de Rondônia (GovRO) que, por meio do decreto N. 22.660 de 14 de março de 2018 (BRASIL, 2018), promulgado pelo então governador Confúcio Aires Moura, institui a Política Estadual de Gestão do Conhecimento.

No âmbito dos órgãos das administrações estaduais têm-se, ainda, a Secretaria de Estado de Fazenda de Minas Gerais (SEF/MG), que tem por finalidade planejar, coordenar, executar e avaliar a política tributária e fiscal, bem como gerir os recursos financeiros necessários à consecução dos objetivos da administração pública estadual, responsabilizandose pelo seu provimento, controle e administração. A proposta de Política de Gestão do Conhecimento da SEF/MG, objeto desta pesquisa, pode ser vista em Oliveira e Silva (2013, p. 22-26). Neste mesmo lócus a Secretaria de Estado de Planejamento e Gestão de Minas Gerais (SEPLAG/MG) regulamentou, por meio da Resolução N. 55, de 27 de julho de 2012 (MINAS GERAIS, 2012), a Política Estadual de Gestão do Conhecimento de Minas Gerais.

Em continuidade, o Instituto de Pesquisa Econômica Aplicada (IPEA) é uma fundação pública federal vinculada ao Ministério do Planejamento, Desenvolvimento e Gestão. Suas atividades de pesquisa subsidiam suporte às ações governamentais para a (re)formulação de políticas públicas e programas de desenvolvimento no Brasil (IPEA, 2018). A Portaria N. 385, de

Perspectivas em Gestão \& Conhecimento, João Pessoa, v. 11, número especial, p. 18-34, mar. 2021. 
13 de outubro de 2010 (IPEA, 2010), institui a Política de Gestão do Conhecimento e Inovação do desse instituto.

As sete organizações, acima descritas, são públicas e atuam nos campos empresarial federal (SERPRO e ECT), gestão Estadual (GovSP, GovRO, SEPLAG/MG e SEF/MG) e de pesquisa (IPEA), constituindo exemplos de políticas de GC instituídas de 2001 a 2018. Isso anuncia que a teoria da GC tem se desenvolvido ao longo dos anos e angariado espaço também nas prática da esfera pública brasileira.

\subsection{Análise e implicações}

Para promover a análise das políticas de GC identificadas nesta pesquisa, primeiramente, foram lidas as descrições dos 13 fatores críticos para o sucesso da GC, apresentados por Corrêa e Carvalho (2019). Após a imbricação mental desses elementos, oriunda da recorrente leitura, partiu-se para a análise de cada política de GC, sendo essa realizada pela interpretação íntegra de cada documento. Durante essa leitura as premissas, políticas e diretrizes apresentadas em cada documento foram situadas mediante aos fatores críticos de sucesso supracitados, sendo este resultado exposto por meio do Quadro 3:

Quadro 3 - Políticas de Gestão do Conhecimento versus Fatores Críticos de Sucesso

\begin{tabular}{|c|c|c|c|c|c|c|c|c|}
\hline & \multicolumn{7}{|c|}{ Organizações com Políticas de GC } \\
\hline & & SERPRO & GovSP & IPEA & SEPLAG/MG & SEF/MG & ECT & GovRO \\
\hline \multirow{13}{*}{ 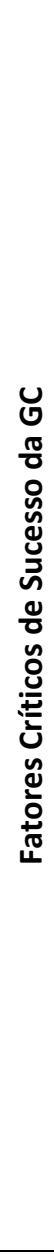 } & ETG & Dir.XIII & & $\begin{array}{l}\text { Art.1ㅇ.I } \\
\text { Art.3‥ }\end{array}$ & Art.3‥III & $\begin{array}{l}\text { Art.5음 } \\
\text { Art.5‥VIII }\end{array}$ & & Art.5‥III \\
\hline & LAA & & & & & & Pol.6, Dir.I & \\
\hline & EGC & & Art.3응 & & Art.3‥VIII & $\begin{array}{l}\text { Art.7ㅇ.VII } \\
\text { Art.11으 }\end{array}$ & & Art.5은 \\
\hline & REC & & & & Art.8응 & Art.18음 & Pol.6, Dir.IV & \\
\hline & PAT & $\begin{array}{l}\text { Pol.1 } \\
\text { Pol.2 } \\
\text { Pol.3 } \\
\text { Dir.IV } \\
\text { Dir.X } \\
\text { Dir.XII }\end{array}$ & $\begin{array}{l}\text { Art.2․․I } \\
\text { Art.2‥VII } \\
\text { Art.2ㅇ.VIII } \\
\text { Art.2‥IX } \\
\text { Art.3‥III }\end{array}$ & $\begin{array}{l}\text { Art.3‥III } \\
\text { Art.3‥V } \\
\text { Art.3‥X }\end{array}$ & $\begin{array}{l}\text { Art.1‥। } \\
\text { Art.1‥II } \\
\text { Art.1ㅇ.III }\end{array}$ & $\begin{array}{l}\text { Art.1‥III } \\
\text { Art.2ㅇ.I } \\
\text { Art.4‥III }\end{array}$ & $\begin{array}{l}\text { Pol.1 } \\
\text { Pol.1.Dir.I } \\
\text { Pol.1.Dir.II } \\
\text { Pol.2.Dir.II } \\
\text { Pol.5.Dir.I } \\
\text { Pol.7.Dir.III }\end{array}$ & $\begin{array}{l}\text { Art.20.I } \\
\text { Art.3․I } \\
\text { Art.3․II }\end{array}$ \\
\hline & GRH & $\begin{array}{l}\text { Pol.5 } \\
\text { Pol.8 }\end{array}$ & & Art.3‥IV & & & Pol.7.Dir.IV & \\
\hline & TED & & & & $\begin{array}{l}\text { Art.6음 } \\
\text { Art.7은 }\end{array}$ & Art.2‥VII & & \\
\hline & MOT & $\begin{array}{l}\text { Pol.8 } \\
\text { Dir.III } \\
\text { Dir.XI }\end{array}$ & & & & & $\begin{array}{l}\text { Pol.1.Dir.III } \\
\text { Pol.7.Dir.II }\end{array}$ & \\
\hline & TEQ & & & Art.3‥VIII & & & & \\
\hline & CUL & & Art.2ㅇ.V & $\begin{array}{l}\text { Art.1‥IV } \\
\text { Art.1ㅇ..V } \\
\text { Art.3‥II }\end{array}$ & $\begin{array}{l}\text { Art.2…II } \\
\text { Art.2‥III }\end{array}$ & Art.2‥II & $\begin{array}{l}\text { Pol.3.Dir.II } \\
\text { Pol.3.Dir.III }\end{array}$ & $\begin{array}{l}\text { Art.2‥II } \\
\text { Art.2‥III }\end{array}$ \\
\hline & TIN & Pol. 9 & Art.2‥X & Art.3‥V & Art.2‥VI & Art.2‥V & Pol.4.Dir.II & \\
\hline & MSR & Pol. 1 & Art.3․IV & $\begin{array}{l}\text { Art.3‥ } \\
\text { Art.3․XIV }\end{array}$ & $\begin{array}{l}\text { Art.2‥V } \\
\text { Art.3‥VIII } \\
\text { Art.5‥III } \\
\text { Art.5‥IV }\end{array}$ & $\begin{array}{l}\text { Art.9․IV } \\
\text { Art.12‥VI }\end{array}$ & & $\begin{array}{l}\text { Art.5‥ } \\
\text { Art.6‥VI }\end{array}$ \\
\hline & PLT & & & & & Art.5응 & & \\
\hline & $\Sigma$ & 6 & 5 & 7 & 8 & 8 & 7 & 5 \\
\hline
\end{tabular}

Legenda: ETG: Estratégia, LAA: Liderança e suporte da alta administração, EGC: Equipe de GC, REC: Recursos (financeiro, humano, material e tempo), PAT: Processos e atividades, GRH: Gestão de recursos

Perspectivas em Gestão \& Conhecimento, João Pessoa, v. 11, número especial, p. 18-34, mar. 2021. 
humanos, TED: Treinamento e educação, MOT: Motivação, TEQ: Trabalho em equipe, CUL: Cultura, TIN: Tecnologia da informação, MSR: Mensuração, PLT: Projeto piloto, Dir.: Diretriz, Art.: Artigo e Pol.: Política.

Fonte: Dados da pesquisa, (2020).

Em relação ao fator Estratégia (ETG), a diretriz XIII do SERPRO assinala "utilizar o Processo de GCO [Gestão do Conhecimento Organizacional] como agente para criar ou aumentar, permanentemente, a percepção de valor, pelos Clientes e Sociedade, dos produtos e serviços do SERPRO" (MACEDO et al., 2001, p. 62). Esta perspectiva ressalta a GC como uma estratégia de negócio que visa a entrega de valor aos stakeholders. Não obstante, a necessidade de um Plano Estratégico de GC é prevista no Art. 50 da SEF/MG (OLIVEIRA; SILVA, 2013 , p. 23) e pelo IPEA na "elaboração, implementação, monitoramento e avaliação de um Plano Estratégico de Gestão do Conhecimento", como disposto no inciso I do Art. 3 (IPEA, 2010, p. 1, grifo nosso), o que estabelece a relação do fator estratégia para com essa gestão.

Por outra perspectiva, o inciso III do artigo Art. 3o da SEPLAG/MG (MINAS GERAIS, 2012 , p. 6, grifo nosso) assume "alinhar o planejamento da gestão do conhecimento com a estratégia de atuação do Governo do Estado de Minas Gerais", assim como a SEF/MG que, por meio do inciso VIII do Art. 50 pretende "alinhar a GC com a Gestão Estratégica da SEF/MG" (OLIVEIRA; SILVA, 2013, p. 25, grifo nosso) e o GovRO, em referência ao inciso III do Art. 5o, visa "garantir o alinhamento do planejamento de Gestão do Conhecimento com a estratégia de atuação do Poder Executivo Estadual" (BRASIL, 2018, p.2, grifo nosso). Em continuidade, o IPEA, por meio do inciso I do Art. 1으, prevê "orientar a mobilização e o tratamento do conhecimento institucional como recurso estratégico" (IPEA, 2010, p. 1, grifo nosso).

Conforme Corrêa e Carvalho (2019), a Estratégia como um fator crítico de sucesso para a GC deve ser clara, bem definida e clarificada aos funcionários para que compreendam os objetivos almejados pela GC. Ademais, essa estratégia deve ser alinhada a estratégia institucional para apoiar seus objetivos. Neste sentido a clarificação aos funcionários é explanada pelo IPEA, enquanto o alinhamento da GC à estratégia organizacional é sinalizado pela SEPLAG/MG, SEF/MG e GovRO. No caso do SERPRO, o objetivo almejado pela GC é a entrega de valor ao cliente, provendo o elo GC-estratégia-negócio. O GovSP e a ECT não apresentaram premissas ou diretrizes atinentes a esse fator.

No que tange a Liderança e suporte da alta administração (LAA), somente a ECT apresentou diretriz atinente a este fator. Corrêa e Carvalho (2009) expressam que o apoio da alta administração atua como um pilar para a continuidade da GC. A política "6. Promoção da GC" tem por primeira diretriz "comprometer as lideranças no processo de GC da ECT" (BATISTA et al., 2014, p. 41). A teoria expressa por este fator confirma-se na ECT, pois essa empresa federal considera que o comprometimento das lideranças é vital para o sucesso da GC.

O fator Equipe de gestão do conhecimento (EGC) incide em uma equipe de profissionais específica com papeis e responsabilidades para promover a GC (CORRÊA; CARVALHO, 2019). O GovSP, por meio do Art. 3ㅇ, assinala o "papel de gestor da Política de Gestão do Conhecimento" (BRASIL, 2009, p. 2, grifo nosso), enquanto a SEPLAG/MG institui no inciso VIII do Art. 3 um "Comitê Executivo Estadual da Política de Gestão do conhecimento" (MINAS GERAIS, 2012, p. 6, grifo nosso), assim como feito no GovRO, por meio do "Art. 5‥ Caberá ao Comitê Estadual de Gestão do Conhecimento" (BRASIL, 2018, p. 2, grifo nosso). Na SEF/MG o inciso VII do Art.70 define o perfil de "Multiplicador de GC, servidor indicado pelo Gerente da Unidade como representante de GC" (OLIVEIRA; SILVA, 2013, p. 24), bem como "uma Equipe Multifuncional de GC" estabelecida no Art. 11으 (OLIVEIRA; SILVA, 2013, p. 25). Isso alude a necessidade de uma equipe orientada a GC e a diversidade de papeis a serem desempenhados nesta condução.

Perspectivas em Gestão \& Conhecimento, João Pessoa, v. 11, número especial, p. 18-34, mar. 2021. 
O fator Recursos (financeiro, humano, material e tempo) (REC) assinala a necessidade de recursos financeiros para sistemas tecnológicos específicos, pessoas para sua condução, insumos materiais e de infraestrutura, bem como tempo para que os funcionários executem os processos e atividades da GC (CORRÊA; CARVALHO, 2019). No Art. 8o a SEPLAG/MG determina o planejamento dos "recursos orçamentários [...] em gestão do conhecimento" (MINAS GERAIS, 2012, p. 6), sendo os mesmos dizeres expressos no Art. 18 da SEF/MG. A ECT assinala na diretriz IV da política "6. Promoção da GC" a necessidade de "prover recursos [...] das ações de GC" (BATISTA et al., 2014, p. 41). Assim como qualquer iniciativa organizacional demanda de recursos, essas políticas expressam que a GC demanda de insumos para sua condução, o que alia a teoria à prática do gerenciamento do conhecimento.

No fator Processos e atividades (PAT) é apresentado o cerne da GC, que resulta em ações como identificação, armazenamento e compartilhamento, que expressam o manuseio do conhecimento (CORRÊA; CARVALHO, 2019). O SERPRO menciona nas alíneas 1,2 e 3 de sua política a "criação", "preservação", "mapeamento" e as diretrizes IV, X e XII as ações "manter", "compartilhamento, reutilização e reconstrução" e "absorção [...] do conhecimento", respectivamente (MACEDO et al., 2001, p. 60-62). A SEPLAG/MG ressalta nos incisos I, II e III do Art. 1 a "geração, estruturação, compartilhamento e disseminação", "uso" e "retenção e a proteção" do conhecimento (MINAS GERAIS, 2012, p. 6). A ECT determina a "geração [...] compartilhamento [...] retenção", "proteção", "absorção", "criação e o compartilhamento", "incorporação" e "atualização do mapeamento" - vide na política 1 e suas diretrizes I e II, política 2 diretriz II, política 5 diretriz I e política 7 diretriz III, respectivamente - (BATISTA et al., 2014, p. 40-41).

Por conseguinte, o IPEA (2010, p. 2) estabelece as ações "acesso" (inciso III do Art. 3ㅇ), "identificação (caracterização), criação (captura, aquisição, coleta); compartilhamento (disseminação, distribuição, partilha, transferência); armazenamento (guarda, repositório); preservação (restauração, acesso para futuro, guarda de longo prazo)" (inciso V do Art. 3) e "transmissão" (inciso X do Art. 3ㅇ). A SEF/MG (OLIVEIRA; SILVA, 2013, p. 22-23) determina a "retenção e proteção do conhecimento gerado por seus servidores" (inciso III do Art. 1ㅇ), o "acesso" (inciso I do Art. 2ㅇ) e a "proteção do conhecimento público" (inciso III do Art. 4ㅇ). O GovRO (BRASIL, 2018, p. 2) anuncia o "acesso" (inciso I do Art. 2ㅇ), "reter e proteger" (inciso I do Art. 3ㅇ) e o "compartilhamento, disseminação e aplicação" (inciso II do Art. 3ㅇ). Do mesmo modo o GovSP (BRASIL, 2009, p. 2-3) institui o "acesso" (incisos VI e VII do Art. 2ㅇ), "compartilhamento" (inciso VIII do Art. 2ํ), "uso" (inciso IX do Art. 2º) e "incorporação" (inciso III do Art. 3ㅇ. A presença deste fator em todas as instituições infere que esse se apresenta como o cerne da GC, bem como evidencia uma desarmonia, haja vista os sinônimos, quanto aos termos empregados para delinear as ações sobre o conhecimento.

Enquanto os PAT apresentam-se como o cerne da GC as pessoas posicionam-se como elementos chaves, pois são as mesmas que aplicarão esses processos no cotidiano institucional. Assim, o fator Gestão de recursos humanos (GRH) é imprescindível, pois seus processos de recrutamento, desenvolvimento e retenção de funcionários municiam a instituição com pessoas detentoras de conhecimento (CORRÊA; CARVALHO, 2019). O processo de desenvolvimento da GRH é definido pelo SERPRO (MACEDO et al., 2001, p. 60-62), por meio da política 5 que determina o "direcionamento dos programas de desenvolvimento das competências individuais e coletivas". Nessa mesma política O SERPRO também determina a "identificação dos Perfis Profissionais", assim como a ECT, por meio da diretriz IV da política 7, institui "identificar os perfis profissionais adequados às atividades das áreas de negócio da ECT" (BATISTA et al., 2014, p. 41), sendo esse um meio para a promoção do processo de recrutamento da GRH. A elo deste fator para com a GC é expresso, precisamente, pela política 8 do SERPRO ao assinalar "a execução da gestão do Capital Intelectual e Humano e sua valorização" (MACEDO et al., 2001, p. 61, grifo nosso), e pelo IPEA (2010, p. 2, grifo nosso), que

Perspectivas em Gestão \& Conhecimento, João Pessoa, v. 11, número especial, p. 18-34, mar. 2021. 
prevê no inciso IV do Art. 3 o "alinhamento dos instrumentos e mecanismos [...] de gestão de pessoas, aos de gestão do conhecimento".

Em relação ao Treinamento e educação (TED), Corrêa e Carvalho (2019) assinalam que os funcionários devem ser treinados e educados para compreender a terminologia e os objetivos da GC, bem como suas responsabilidades perante a essa iniciativa e demais aspectos. A SEPLAG/MG prevê isso ao determinar, no Art. 6ํ, a "qualificação do corpo funcional nas áreas de gestão do conhecimento" e a "capacitação dos servidores acerca de temas afetos à gestão do conhecimento", conforme Art. 70 (MINAS GERAIS, 2012, p. 6). Do mesmo modo, a SEF/MG assinala no inciso VII do Art. 20 o "desenvolvimento de ações de capacitação com foco em GC" (OLIVEIRA; SILVA, 2013, p. 22). É plausível inferir que essas duas instituições percebem que os funcionários devem compreender claramente os termos e temas da GC para, efetivamente, aplicarem seus processos conscientemente.

No que tange o fator Motivação (MOT) têm-se o delineamento de meios para incentivar os funcionários para que se envolvam, compartilhem seus conhecimentos e atuem de forma colaborativa com a GC. Alguns incentivos assinalados por Corrêa e Carvalho (2019) são recompensas (financeiras), gratificações (benefícios não financeiros) e reconhecimento aos funcionários. O SERPRO (MACEDO et al., 2001, p. 60-62) prevê a valorização do Capital Humano (política 8 supracitada), "incentivar e reconhecer" a participação de especialistas como instrutores (diretriz III) e a geração de conhecimento que melhorem os serviços e negócios (diretriz XI). A ECT (BATISTA et al., 2014, p. 40-41) assinala "incentivar e reconhecer a geração de conhecimentos que promovam o aperfeiçoamento" do negócio (diretriz III da política 1) e "incentivar o desenvolvimento de competências" (diretriz II da política 7). Ambas não determinam os tipos de recompensas conferidas para a melhoria do negócio institucional. Contudo, a ECT assinala que um incentivo dá-se pelo desenvolvimento de competências, podendo ser inferido, por exemplo, o custeio de formações acadêmicas como recompensa. Embora uma política não necessariamente prescreva como fazer, pois consiste em orientações normativas, pode ser relevante clarificar os meios para uma interpretação assertiva pelos funcionários.

Quanto ao Trabalho em equipe (TEQ), estar em equipe impulsiona a cooperação entre as pessoas e eleva o sucesso dos processos e atividades da GC. Desse modo, as equipes de trabalho são benéficas à criação e compartilhamento do conhecimento organizacional (CORRÊA; CARVALHO, 2019). Somente o IPEA (2010, p. 2, grifo nosso) assinala, no inciso VIII do Art. 3으, "Promover a cooperação e a colaboração da força de trabalho e equipes no compartilhamento do conhecimento organizacional", o que revela harmonia entre a teoria acadêmica e a prática institucional promulgada pela política de GC instituída por esse instituto federal.

A Cultura (CUL) é um fator conformado por parâmetros de valores, normas e costumes sociais que moldam a forma como as pessoas se comportam. Para a GC uma cultura propícia deve fomentar a partilha do conhecimento, dentre outros aspectos que regem uma atmosfera voltada ao conhecimento (CORRÊA; CARVALHO, 2019). O inciso V do Art. 2 do GovSP (BRASIL, 2009, p. 1) e os incisos II e III do Art. 20 do GovRO preveem o "desenvolvimento da cultura" orientada ao compartilhamento do conhecimento e colaboração, respectivamente. Desenvolver, promover ou incentivar uma cultura profícua a GC são outras formas utilizadas para este fator nos incisos II e III do Art. 20 da SEPLAG/MG, inciso II do Art. 20 da SEF/MG, diretriz II e III da política 3 da ECT, incisos IV e V do Art. 10 e inciso II do Art. 3ㅇ do IPEA.

O fator Tecnologia da informação (TIN) conecta as pessoas em prol do compartilhamento do conhecimento tácito, bem com permite que o conhecimento explícito seja armazenado e compartilhado na organização, pelo uso de banco de dados, intranet e internet (CORRÊA; CARAVALHO, 2019). O uso de tecnologias da informação como suporte à promoção da GC é previsto pela política 9 do SERPRO, inciso X do Art. 2 do GovSP, inciso VI do

Perspectivas em Gestão \& Conhecimento, João Pessoa, v. 11, número especial, p. 18-34, mar. 2021. 
Art. 2ㅇ da SEPLAG/MG, diretriz II da política 4 da ECT, inciso $V$ do artigo 3을 do IPEA, enquanto a SEF/MG assinala, no inciso $V$ do Art. $2^{\circ} \circ$, o uso de ferramentas e aplicações tecnológicas. $O$ GovRO não demarca, de forma explícita, o emprego deste fator. São amplas as possibilidades de uso da tecnologia em iniciativas organizacionais e, portanto, não havendo direcionamento de como utilizá-la cabe a cada organização supramencionada determinar, mediante a percurso da GC, como empregar a tecnologia para esse fim.

Segundo Corrêa e Carvalho (2019), a Mensuração (MSR) visa medir o conhecimento para avaliar o progresso e a melhoria contínua do programa de GC, acarretando na necessidade de determinar metas mensuráveis. Um instrumento é o diagnóstico, que tende a mensurar aspectos para identificar lacunas a serem sanadas mediante ao gerenciamento do conhecimento. Mensurar os resultados e benefícios da GC é uma ação prevista na política 1 do SERPRO, inciso XIV do Art. 30 do IPEA e inciso IV do Art. 9o da SEF. No mesmo sentido o termo avaliação é utilizado como sinônimo de mensuração pela política 1 do SERPRO, inciso $V$ do Art. 20 da SEPLAG/MG e do GovRO e inciso IV do Art. 3 do GovSP. Somente a SEPLAG/MG - inciso VIII do Art. $30-$ e a SEF/MG - inciso VI do Art. 12- assinalam o uso de indicadores, métricas e, ou, metas para a mensuração, enquanto o IPEA - inciso I do Art. 3 - visa avaliar o grau de maturidade da GC por meio de um diagnóstico. A divulgação dos resultados obtidos por meio desta iniciativa é previsto pelo GovSP e IPEA nas alíneas supracitadas, enquanto o SEPLAG, por meio do incisos III e IV do Art. 50, e o GovRO, por meio do inciso V do Art. 5o e inciso VI do Art. 60 , preveem fazê-lo pela emissão de um relatório específico e periódico - semestral e, ou, anual - de GC. Por essas determinações a mensuração e o diagnóstico confirmam-se como meios de medir o andamento do gerenciamento do conhecimento, sendo também previsto a divulgação de seus resultados por meio de relatórios dedicados. Não obstante, somente a ECT não delineou ação de mensuração.

O fator Projeto piloto (PLT) consiste em uma forma de pôr em prática a GC em menor amplitude institucional para captar os erros e obter lições aprendidas, elevando o sucesso de uma iniciativa quando aplicada em maior abrangência (CORRÊA; CARVALHO). Somente a SEF/MG apresenta esse fator no seguinte trecho: "Art. 5o [...] Plano Estratégico da Gestão do Conhecimento [...] Contempla ainda a metodologia utilizada no piloto do Projeto de GC na SEF/MG" (OLIVEIRA; SILVA, 2013, p. 23, grifo nosso). Desse modo, é prevista a implantação de um projeto piloto de GC antes de sua promoção em maior amplitude organizacional. A Figura 1 ilustra os 13 fatores e seus aspectos (grifo) com as organizações que os contemplam.

Todas as organizações analisadas são públicas, sendo empresas e instituto, bem como secretarias da esfera federal e estadual, respectivamente. As secretarias SEPLAG/MG e SEF/MG contemplam 8 dos 13 fatores críticos de sucesso da GC, sendo sucedidas pelo instituto IPEA e empresa ECT com 7 fatores, empresa SERPRO com 6 e GovSP e GovRO com 5. Contudo, nenhuma dessas instituições contempla todas as nuances da GC. Isso rompe com a perspectiva representada por Souza (2006 p. 25, grifo nosso) de que uma política assume "uma visão holística do tema, de que o todo é mais importante do que a soma das partes". Também cessa com a ótica de Corrêa e Carvalho (2019) de que todas as partes críticas devem ser contempladas em conjunto. Em comunhão, as políticas de GC analisas mediante as perspectivas dos estudos supramencionados tendem a não contemplar o gerenciamento do conhecimento de forma holística. 
Figura 1 - Fatores Críticos de Sucesso contemplados por Políticas de Gestão do Conhecimento

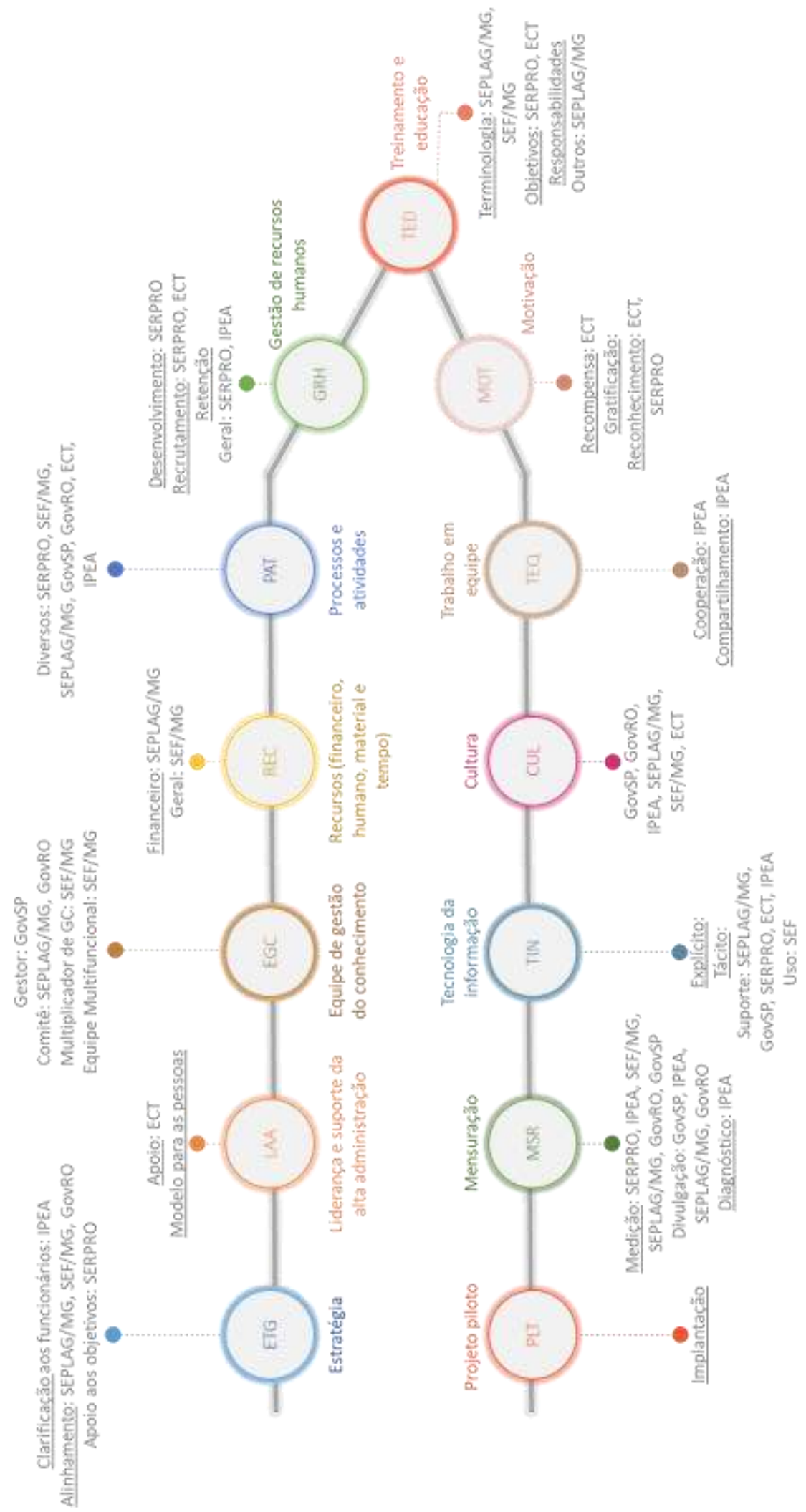

Fonte: Dados da pesquisa (2020)

Perspectivas em Gestão \& Conhecimento, João Pessoa, v. 11, número especial, p. 18-34, mar. 2021. 


\section{CONCLUSÕES}

Por meio da análise realizada nesta pesquisa conclui-se, primeiramente, que não há uma política de GC, dentre as sete analisadas, que contemple todos os fatores críticos para o sucesso do gerenciamento do conhecimento. Devido a isso há possibilidade considerável dessas iniciativas não atingirem o êxito integral, haja vista que algumas partes (fatores) impreteríveis não foram contemplados nas respectivas políticas. Por conseguinte, considerando a perspectiva de Souza (2006) de que uma política assume uma visão holística sobre o tema que versa e, conforme Corrêa e Carvalho (2019), nisso incide contemplar todas suas partes em conjunto, conclui-se, por silogismo lógico, que as políticas analisadas não contemplam a GC de forma holística.

Em terceiro, é possível concluir que há convergência entre teoria e prática, pois todos os fatores foram contemplados por pelo menos uma política de GC e todas as políticas contemplam mais de um fator. Desse modo, a teoria acadêmica tem respaldo e abrangência na prática organizacional, bem como a prática contribui para o desenvolvimento teórico, culminando em uma relação bidirecional contributiva.

Esta pesquisa está alicerçada na seguinte interrogativa: em que nível as políticas de GC tem contemplado os fatores críticos para o sucesso dessa iniciativa? Mediante as análises realizadas, têm-se uma média de 6,57 fatores analisados entre as políticas investigadas - soma dos fatores contemplados nas políticas dividido pelo número de políticas, sendo $(6+5+7+8+8+7+5) / 7$, conforme Quadro $3-$, culminando na abordagem média de menos da metade dos 13 fatores considerados impreteríveis para o sucesso da GC no espaço temporal de políticas publicadas de 2001 a 2018. Nisso incide uma oportunidade de avanço, pois as combinações de políticas, como as da SEF/MG e ECT, culminam no atingimento de todos os fatores supracitados.

Diante do exposto, esta pesquisa tende a contribuir com organizações que elaborem novas políticas com vistas a contemplar a GC de forma holística. Contudo, cabe ressaltar que uma política estabelece, de modo normativo, o que deve ser feito em determinado contexto, sendo um instrumento que promulga norteamentos que impactam outrem. Mas, sua aplicação prática deverá seguir os preceitos estabelecidos para que o êxito do gerenciamento do conhecimento possa ser atingido. Dito de outro modo, as premissas e diretrizes "teóricas" devem ser operacionalizadas na prática para que o ambicionado seja, de fato, atingido como estabelecido.

\section{REFERÊNCIAS}

BARDIN, L. Análise de conteúdo. Lisboa: Edições 70, 1977.

BATISTA, F. F. et al. Casos reais de implantação do modelo de gestão do conhecimento para a administração pública brasileira. Texto para Discussão 1941, Instituto de Pesquisa Econômica Aplicada (IPEA), $2014 . \quad$ Disponível em: http://repositorio.ipea.gov.br/bitstream/11058/2877/5/TD 1941 Vers\%c3\%a30\%20revista.pd f>. Acesso em: 18 mai. 2020.

BRASIL. A experiência brasileira na formulação de uma proposta de política de gestão do conhecimento para a administração pública federal. Brasília: Câmara dos Deputados, 2007. Disponível em: <http://www.bibl.ita.br/PoliticaGC.pdf>. Acesso em 16 mai. 2020. 
BRASIL. Decreto no 22.600 de 14 de Março de 2018. Política Estadual de Gestão do Conhecimento do Governo do Estado de Rondônia. São Paulo, 2018.

BRASIL. Decreto no 53.963 de 21 de Janeiro de 2009. Política de Gestão do Conhecimento e Inovação do Governo do Estado de São Paulo. São Paulo, 2009.

CAPRA, F. A teia da vida: uma nova compreensão científica dos sistemas vivos. 9 ed. São Paulo: Cultrix, 2000.

CAPRA, F. A visão sistêmica da vida: uma concepção unificada e suas implicações filosóficas, políticas, sociais e econômicas. São Paulo: Cultrix, 2014.

CARVALHO, I. M.; MENDES, S. P.; VERAS, V. M. (orgs). Gestão do conhecimento: uma estratégia empresarial. Brasília: J. J. Gráfica e Comunicações, 2006.

CARVALHO, R. B. Aplicações de Softwares de Gestão do Conhecimento: Tipologia e Usos. 2000. 144 f. Dissertação (Mestrado em Ciência da Informação) Escola de Ciência da Informação, Universidade Federal de Minas Gerais - UFMG, Belo Horizonte, 2000.

CORRÊA, F. A Gestão do Conhecimento holística e a aderência do modelo Fivaz e Pretorius. Transinformação, v. 32, p. 1-9, 2020.

CORRÊA, F.; CARVALHO, D. B. F. Holistic knowledge management: adherence analysis of the Castillo and Cazarini model. Knowledge Management Research \& Practice, v. published online, p. 1-11, 2019. DOI https://doi.org/10.1080/14778238.2019.1701963

CREMA, R. Introdução à visão holística: breve relato de viagem do velho ao novo paradigma. 6ed. São Paulo: Summus, 2015.

FTEIMI, N. Analyzing the literature on knowledge management frameworks: Towards a normative knowledge management classification schema. In: European Conference on Information Systems (ECIS), 23., 2015, Alemanha. Anais... Alemanha: Münster, 2015, p.1-16.

GIL, A. C. Métodos e técnicas de pesquisa social. 4. ed. São Paulo: Atlas, 2002.

GONÇALVES, S. M. G. Elementos básicos para a formulação de uma Política de Gestão do Conhecimento para a Administração Pública Federal brasileira, 2006, 140 f. Dissertação (Mestrado em Gestão do Conhecimento e da Tecnologia da Informação) - Programa de PósGraduação em Gestão do Conhecimento e da Tecnologia da Informação, Universidade Católica de Brasília, 2006.

GONZALEZ, R. V. D.; MARTINS, M. F.; MELO, T. M. Gestão do conhecimento: tipologia a partir dos fatores contextuais da organização. Transinformação, v.30, n.2, p.249-266, 2018.

HEISIG, P. Harmonisation of knowledge management - comparing $160 \mathrm{KM}$ frameworks around the globe. Journal of Knowledge Management, v.13, n.4, p.4-31, 2009.

HOLSAPPLE, C. W.; JOSHI, K. D. Description and analysis of existing knowledge management frameworks. In: Annual Hawaii International Conference on Systems Sciences (HICSS), 32. 1999, Estados Unidos. Anais... Estados Unidos: Maui, 1999, p.1-15.

Perspectivas em Gestão \& Conhecimento, João Pessoa, v. 11, número especial, p. 18-34, mar. 2021. 
IPEA - INSTUTUTO DE PESQUISA ECONÔMICA APLICADA. Portaria no 385, de 13 de outubro de 2010. Institui, no âmbito do Ipea, a Política de Gestão do Conhecimento e Inovação e dá outras providências. Brasília: Ipea, 2010.

IPEA - INSTUTUTO DE PESQUISA ECONÔMICA APLICADA. Quem somos. Disponível em: http://www.ipea.gov.br/portal/index.php?option=com content\&view=article\&id=1226\&ltemi $\mathrm{d}=68 \mathrm{http}: / / \mathrm{www}$.ipea.gov.br/portal/index.php?option=com content\&view=article\&id=1226\&l temid=68. Acesso em 16 set. 2018.

MACIEL, C. M.; SILVA, A. F. Gerenciando pessoas utilizando modelos holísticos. Revista da Administração Contemporânea - RAC, v. 12, n. 1, p. 35-58, 2008.

MINAS GERAIS. Secretaria de Planejamento e Gestão de Minas Gerais (SEPLAG/MG). Resolução no 55, de 27 de julho de 2012. Belo Horizonte: Seplag, 2012. Disponível em: < http://jornal.iof.mg.gov.br/xmlui/bitstream/handle/123456789/68225/caderno1 2012-0728\%206.pdf?sequence=1>. Acesso em 18 mai. 2020.

MINAYO, M. C. S. O desafio do conhecimento: pesquisa qualitativa em saúde. 5. ed. São Paulo: Hucitec, 1998.

NATALE, C. H. C.; NEVES, J. T. R.; CARVALHO, R. B. Maturidade em gestão do conhecimento: análise das percepções dos gestores de uma grande empresa de construção civil. Informação \& Informação, v.21, n.1, p. 375-406, 2016.

OLIVEIRA, S. C. A.; SILVA, G. P. A. Gestão do conhecimento (GC) na Secretaria de Estado da Fazenda de Minas Gerais (SEF/MG): O desafio da construção e implantação de um modelo de GC alicerçado na gestão estratégica governamental. In: VI Congresso CONSAD de Gestão Pública, Brasília, Distrito Federal, 16, 17 e 18 de abril de 2013. Anais... VI CONSAD, 2013. Disponível em: < http://www.sgc.goias.gov.br/upload/arquivos/2014-04/gestod 1.pdf>. Acesso em: 19 mai. 2020.

PEREIRA, M. F. A gestão organizacional em busca do comportamento holístico. In: ANGELONI, M. T. Organizações do conhecimento: infra-estrutura, pessoas e tecnologia. São Paulo: Saraiva, 2002, p.2-28.

PROCOPIUCK, M. Políticas públicas e fundamentos da administração pública: análise e avaliação, governança e redes de políticas, administração judiciária. São Paulo: Atlas, 2013.

RAMALHO, W.; LOCATELLI, R. L.; SILVA, S. C. D. Análise organizacional sob a ótica da teoria da complexidade: proposição e aplicação de um modelo. Revista Gestão \& Tecnologia, v.18, n.2, p.200-223, 2018.

RUBENSTEIN-MONTANO, B. et al. A systems thinking framework for knowledge management. Decision Support Systems, v.31, n.1, p.5-16, 2001.

SERPRO - SERVIÇO FEDERAL DE PROCESSAMENTO DE DADOS. Quem somos. Disponível em: http://www.serpro.gov.br/menu/institucional/quem-somos. Acesso em 18 mai. 2020.

SILVEIRA, M. A. S. G. et al. Gestão de processo de compartilhamento do conhecimento tecnológico em uma empresa do setor elétrico (CEMIG). Informação \& Informação, v.23, n.2, p.538-565, 2018.

Perspectivas em Gestão \& Conhecimento, João Pessoa, v. 11, número especial, p. 18-34, mar. 2021. 
SOUZA, C. Políticas públicas: uma revisão da literatura. Sociologias, n. 16, p. 20-45, 2006.

WEIL, P. O novo paradigma holístico: ondas a procura do mar. In: BRANDÃO, Dênis. M. S.; CREMA, R. (orgs). O novo paradigma holístico: ciência, filosofia, arte e mística. São Paulo: Summus, p. 14-38, 1991. 